\title{
Comportamento ingestivo em caprinos alimentados com dietas contendo cana-de-açúcar tratada com óxido de cálcio ${ }^{1}$
}

\section{Gleidson Giordano Pinto de Carvalho ${ }^{2,8}$, Rasmo Garcia ${ }^{3,8}$, Aureliano José Vieira Pires ${ }^{4,7}$, Edenio Detmann ${ }^{3,8}$, Leandro Sampaio Oliveira Ribeiro ${ }^{5}$, Daiane Maria Trindade Chagas ${ }^{6}$, Robério Rodrigues Silva ${ }^{7,8}$, Bianca Damasceno Pinho ${ }^{6}$}

\author{
1 Projeto financiado pelo CNPq. \\ 2 Departamento de Produção Animal/UFBA, Salvador, BA. \\ ${ }^{3}$ Departamento de Zootecnia/UFV, Viçosa, MG. \\ ${ }^{4}$ Departamento de Tecnologia Rural e Animal/UESB, Itapetinga, BA. \\ 5 IFbaiano, campus de Uruçuca, BA. \\ ${ }^{6}$ Graduando em Zootecnia/UESB, Itapetinga, BA. \\ 7 Departamento de Estudos Básicos e Instrumentais/UESB, Itapetinga, BA. \\ 8 Pesquisador do CNPq.
}

RESUMO - Objetivou-se avaliar o efeito do tratamento da cana-de-açúcar com óxido de cálcio (CaO) sobre o comportamento ingestivo em caprinos. Foram utilizados oito caprinos da raça Saanen, machos castrados, com peso corporal médio de 22,6 kg e 4 meses de idade, distribuídos em dois quadrados latinos $4 \times 4$, com quatro períodos experimentais de 14 dias. Os animais foram mantidos em baias individuais de $1,2 \mathrm{~m}^{2}$, com piso ripado de madeira, providas de comedouros e bebedouros individuais. As dietas foram formuladas para ser isoproteicas e conter $14 \%$ de proteína bruta (PB) e apresentaram $70 \%$ de cana-de-açúcar tratada com 0; 0,$75 ; 1,5$ ou 2,25\% de óxido de cálcio (com base na matéria natural) corrigida com 1\% de ureia e 30\% de concentrado fornecidas a vontade. A cana-de-açúcar com a adição das doses de óxido de cálcio, foi triturada em desintegradora estacionária, pesada e acondicionada em baldes plásticos de 50 L, tratada com o óxido de cálcio e fornecida aos animais após 24 horas de armazenamento. Os tempos despendidos em alimentação, ruminação (min/dia, min/kg MS e min/kg FDN) e ócio (min/dia) não foram afetados pela adição de óxido de cálcio à cana-de-açúcar. A adição de óxido de cálcio à cana-de-açúcar não influenciou a eficiência em alimentação e ruminação, mas provocou redução do tempo médio despendido por período de alimentação. O comportamento ingestivo de caprinos em crescimento não é afetado pela utilização de dietas contendo cana-de-açúcar tratada com até 2,25\% de óxido de cálcio.

Palavras-chave: alimentação, cal, ócio, ruminação

\section{Ingestive behavior in goats fed diets containing sugar cane treated with calcium oxide}

\begin{abstract}
The objective of this work was to evaluate the effect of sugar cane treated with calcium oxide $(\mathrm{CaO})$ on ingestive behavior in goats. It was used eight castrated male Saanen goats, with $22.6 \mathrm{~kg}$ average body weight and at four months of age, distributed in two $4 \times 4$ Latin squares, with four 14-day experimental periods. The animals were kept in individual $1.2-\mathrm{m}^{2}$ stalls, with wood battened floor, provided with individual feeders and drinkers. The diets were formulated to be isoproteic, with $14 \%$ crude protein (CP) and presented $70 \%$ sugar cane treated with $0 ; 0.75$; 1.5 or $2.25 \%$ of calcium oxide (on natural matter basis) corrected with $1 \%$ urea and $30 \%$ of concentrate fed ad libitum. Sugar cane added with doses of calcium oxide was crushed in stationary chopper, weighed and stored in 50-L plastic buckets and treated with calcium oxide, given to the animals after 24 hours of storage. Times spent in feeding, ruminating (min/day; min/kg DM and min/kg NDF) and idle (min/day) were not affected by addition of calcium oxide to sugar cane. Addition of calcium oxide to sugar cane did not influence effciency of feeding and rumination mad it reduced average time spent per feeding period. Ingestive behavior of growing goats is not affected by utilization of diets with sugar cane treated with up to $2.25 \%$ of calcium oxide.
\end{abstract}

Key Words: feeding, idle, lime, rumination

\section{Introdução}

Os caprinos desenvolveram adaptações anatômicas e fisiológicas para se alimentarem de uma ampla variedade de alimentos. Ribeiro (2003), entretanto, afirmou que a estratégia de alimentação desses animais é baseada primariamente na qualidade nutritiva do alimento, verificando-se redução na ingestão de matéria seca, geralmente, em condições de altas taxas de lotações, pois provoca diminuição na qualidade nutritiva do extrato forrageiro devido à seleção e consumo 
de partes mais digestíveis. Outro fator que provoca redução na ingestão de matéria seca é baixa qualidade forrageira em períodos de escassez, na qual coincide com a baixa precipitação pluviométrica em diversas regiões do país.

A cana-de-açúcar nesse sentido constitui-se em boa alternativa alimentar para ruminantes nos períodos de seca. Segundo Evangelista et al. (2003), a cana-de-açúcar possuindo um enorme potencial como forrageira, em razão de ser uma cultura permanente de fácil implantação e cultivada em todo território brasileiro, com poucos tratos culturais e elevados rendimentos de forragem (mais de 120 t/ha) em uma única colheita. A época de colheita coincide ainda com o período de baixa disponibilidade de pasto, apresentando elevado conteúdo de sacarose no colmo, com manutenção do valor nutritivo por período de tempo suficiente para ser colhida de acordo com a necessidade.

O elevado teor de fibra de baixa digestibilidade na canade-açúcar, entretanto, constitui-se fator limitante de sua plena utilização na alimentação de ruminantes. O tratamento químico da cana-de-açúcar com a utilização de produtos químicos, como o óxido de cálcio (Balieiro Neto et al., 2007; Ribeiro et al., 2009), é uma realidade, que necessita de maiores estudos para além de estudar a composição química, avaliar também as possíveis modificações no comportamento ingestivo de animais submetidos a materiais tratados quimicamente (Carvalho et al., 2008).

Assim, objetivou-se avaliar o efeito do tratamento da cana-de-açúcar com doses de óxido de cálcio sobre o comportamento ingestivo de caprinos em crescimento.

\section{Material e Métodos}

O experimento foi conduzido no Setor de Caprinocultura e no Laboratório de Forragicultura e Pastagens da Universidade Estadual do Sudoeste da Bahia, no Campus de Itapetinga, Bahia. Foram utilizados oito caprinos da raça Saanen, machos, castrados, com peso corporal médio inicial de 22,6 kg e quatro meses de idade, distribuídos em dois quadrados latinos $4 \times 4$.

Os animais foram mantidos em baias individuais de $1,2 \mathrm{~m}^{2}$ com piso ripado de madeira, providas de comedouros e bebedouros, dispostos frontalmente em cada baia e alimentados com dietas contendo $70 \%$ de cana-de-açúcar tratada com doses de 0; 0,75; 1,5 e 2,25\% de óxido de cálcio $(\mathrm{CaO})$ e $30 \%$ de concentrado. A cana-de-açúcar sem tratamento ( $0 \%$ de $\mathrm{CaO}$ ), foi desintegrada previamente ao fornecimento da dieta. Já a cana-de-açúcar com a adição das doses de $\mathrm{CaO}$, foi triturada em desintegradora estacionária, pesada, acondicionada em baldes plásticos de 50 litros e tratada com as doses de $\mathrm{CaO}$, na base da matéria natural, sem diluir em água, sendo fornecida aos animais após 24 horas de armazenamento.

Tanto a cana sem tratamento $(0 \%$ de $\mathrm{CaO})$ como a tratada $(0,75 ; 1,5$ e $2,25 \%$ de $\mathrm{CaO})$, foi corrigida com $1,0 \%$ ureia na base da matéria natural, mediante a diluição em água, obedecendo a proporção de $1 \mathrm{~kg}$ de ureia para $4 \mathrm{~L}$ de água. As dietas foram calculadas para conterem nutrientes suficientes para ganho de peso de $0,2 \mathrm{~kg} / \mathrm{dia}$ (NRC, 2006), com aproximadamente $14 \%$ de proteína bruta.

A composição percentual e nutricional das dietas experimentais podem ser observadas nas Tabelas 1 e 2, respectivamente. Durante todo o experimento, antes do fornecimento das dietas, foi realizado o monitoramento do teor de açúcares solúveis ( ${ }^{\circ}$ Brix) da cana-de-açúcar in natura e com as doses de $\mathrm{CaO}$ utilizando refratômetro, o qual apresentou média de $20,3^{\circ}$ Brix.

Tabela 1 -Composição percentual dos ingredientes do concentrado e da dieta (\% na MS)

\begin{tabular}{lcc}
\hline Ingrediente & Concentrado & Dieta \\
\hline Cana de açúcar ${ }^{1}$ & - & 70,0 \\
Fubá de milho & 55,7 & 16,8 \\
Farelo de soja & 36,2 & 10,9 \\
Fosfato bicálcico & 2,3 & 0,7 \\
Mistura mineral & 5,8 & 1,6 \\
\hline${ }^{2}$ Cana-de-açúcar com diferentes doses de óxido de cálcio (0, 0,75; 1,5 ou 2,25\% \\
na MN) e adicionada de 1\% de ureia (\%MN). \\
${ }^{2}$ Quantidade/kg do produto: cálcio - 120 g; fósforo - 60 g; enxofre - 12 g; \\
magnésio - 6 g; sódio - 111 g; zinco - 6.000 mg; cobre - 100 mg; ferro - 1.000 mg; \\
cobalto - 200 mg; níquel - 42 mg, manganês - 1.400 mg.
\end{tabular}

Tabela 2 - Composição nutricional das dietas experimentais

\begin{tabular}{|c|c|c|c|c|}
\hline \multirow[t]{2}{*}{ Item } & \multicolumn{4}{|c|}{ lo de cálcio na cana-de-açúcar ${ }^{1}$} \\
\hline & 0 & 0,75 & 1,5 & 2,25 \\
\hline Matéria seca, MS & 45,8 & 46,1 & 46,9 & 47,8 \\
\hline Matéria orgânica (\%MS) & 94,7 & 93,1 & 91,6 & 90,3 \\
\hline Proteína bruta (\%MS) & 14,8 & 14,8 & 14,7 & 14,9 \\
\hline PIDN (\%PB) & 17,2 & 16,1 & 15,8 & 18,7 \\
\hline PIDA (\%PB) & 7,3 & 8,9 & 6,7 & 7,7 \\
\hline Extrato etéreo (\%MS) & 2,4 & 2,5 & 2,1 & 2,0 \\
\hline Cinzas (\%MS) & 5,3 & 6,9 & 8,4 & 9,7 \\
\hline Carboidratos totais (\%MS) & 75,4 & 74,4 & 73,3 & 72,1 \\
\hline Fibra em detergente neutro (\%MS) & 43,7 & 45,0 & 42,2 & 39,6 \\
\hline FDNcp (\%MS) & 39,5 & 41,0 & 37,8 & 35,1 \\
\hline FDNi (\%MS) & 22,4 & 23,1 & 19,9 & 16,8 \\
\hline FDNpd & 21,3 & 21,9 & 22,3 & 22,9 \\
\hline Carboidratos não-fibrosos (\%MS) & 31,6 & 29,4 & 31,1 & 32,5 \\
\hline CNFcp (\%MS) & 35,8 & 33,4 & 35,5 & 37,0 \\
\hline Fibra em detergente ácido (\%MS) & 28,4 & 29,7 & 26,5 & 26,2 \\
\hline FDAi (\%MS) & 18,1 & 17,8 & 17,4 & 12,9 \\
\hline Hemicelulose (\%MS) & 15,3 & 15,3 & 15,7 & 13,5 \\
\hline Celulose (\%MS) & 24,0 & 24,4 & 21,9 & 21,8 \\
\hline Lignina (\%MS) & 5,4 & 5,3 & 4,6 & 4,3 \\
\hline MSpD (\%MS) & 78,8 & 78,2 & 81,2 & 84,3 \\
\hline MSi (\%MS) & 25,4 & 26,5 & 22,8 & 19,6 \\
\hline NDT $(\% M S)^{2}$ & 64,3 & 62,7 & 63,0 & 62,8 \\
\hline
\end{tabular}

R. Bras. Zootec., v.40, n.8, p.1767-1773, 2011 
O experimento teve duração de 56 dias, constituído de quatro períodos experimentais de 14 dias cada, sendo os dez primeiros dias destinados à adaptação dos animais e os quatro dias finais para coleta de dados.

As dietas foram fornecidas à vontade, duas vezes ao dia, às $7 \mathrm{~h}$ e às $15 \mathrm{~h}$, sendo ajustadas de forma a manter as sobras em torno de 5 a $10 \%$ do fornecido, com água permanentemente à disposição dos animais. Durante todo o experimento, os alimentos oferecidos foram registrados diariamente. No período de coleta, $11^{\underline{0}}$ ao $14^{\circ}$ dia de cada período experimental, amostras dos volumosos, concentrado e das sobras de cada animal foram coletadas diariamente, acondicionadas em sacos plásticos e armazenadas em freezer, para posterior análises e estimação do consumo de matéria seca e fibra.

Na avaliação do comportamento ingestivo dos animais, os mesmos foram submetidos a períodos de observação visual durante dois dias, ao final de cada período experimental, sendo a primeira observação no 12 으 dia de cada período experimental. Neste dia os animais foram observados durante 24 horas, em intervalos de cinco minutos, para a avaliação dos tempos de alimentação, ruminação e ócio. Durante a observação noturna, o ambiente foi mantido com iluminação artificial.

No dia seguinte, $13^{\circ}$ o dia, foram realizadas três observações em cada animal em três períodos diferentes: manhã, tarde, noite. Nestes períodos, foi observado o número de mastigações por bolo ruminal e contabilizado o tempo gasto para ruminação de cada bolo. Este procedimento foi realizado com o auxílio de cronômetros digitais, manuseados por quatro observadores, que se posicionaram em frente às baias de forma a não incomodar os animais.

Na estimativa das variáveis comportamentais alimentação e ruminação (min/kg MS e FDNcp), eficiência alimentar (g MS e FDN/hora), eficiência em ruminação (g de MS e FDNcp/bolo e g MS e FDNcp/hora) e consumo médio de MS e FDNcp por período de alimentação, considerou-se o consumo voluntário de MS e FDN do $12^{\circ}$ e e $13^{\circ}$ dia de cada período experimental, sendo as sobras computadas entre o $13^{\circ}$ ao $14^{\circ}$ dia.

O número de bolos ruminados diariamente foi obtido da seguinte forma: tempo total de ruminação (min) divido pelo tempo médio gasto na ruminação de um bolo. A concentração de MS e FDNcp em cada bolo (g) ruminado foi obtida a partir da divisão quantidade de MS e FDNcp consumida (g/dia) em 24 horas pelo número de bolos ruminados diariamente.

A eficiência de alimentação e ruminação foi obtida da seguinte forma:

$\mathrm{EAL}_{\mathrm{MS}}=\mathrm{CMS} / \mathrm{TAL}$;

\section{$\mathrm{EAL}_{\mathrm{FDN}}=\mathrm{CFDN} / \mathrm{TAL}$} em que: $\mathrm{EAL}_{\mathrm{MS}}$ (g MS consumida/h); $\mathrm{EAL}_{\mathrm{FDN}}(\mathrm{g}$ FDN consumida/hora) = eficiência de alimentação; CMS (g) = consumo diário de matéria seca; $\mathrm{CFDN}$ (g) = consumo diário de FDN; TAL = tempo gasto diariamente em alimentação. $\mathrm{ERU}_{\mathrm{MS}}=\mathrm{CMS} / \mathrm{TRU}$;

$\mathrm{ERU}_{\mathrm{FDN}}=\mathrm{CFDN} / \mathrm{TRU}$;

em que: $\mathrm{ERU}_{\mathrm{MS}}$ (g MS ruminada/h); $\mathrm{ERU}_{\mathrm{FDN}}$ (g FDN ruminada/h) = eficiência de ruminação e TRU (h/dia) = tempo de ruminação.

$\mathrm{TMT}=\mathrm{TAL}+\mathrm{TRU}$;

em que: TMT $(\mathrm{min} /$ dia $)=$ tempo de mastigação total.

Os cálculos acima foram realizados conforme Carvalho et al. (2006a).

O número de períodos de alimentação, ruminação e ócio foram contabilizados pelo número sequências de atividades observadas na planilha de anotações. A duração média diária desses períodos de atividades foi calculada dividindo-se a duração total de cada atividade (alimentação, ruminação e ócio em min/dia) pelo seu respectivo número de períodos discretos.

Amostras dos volumosos, concentrados e sobras de cada animal foram pré-secas em estufa com ventilação forçada a $60^{\circ} \mathrm{C}$ e processadas em moinho de faca (peneira com crivos de $1 \mathrm{~mm}$ ), sendo os teores de matéria seca (MS), matéria orgânica (MO), proteína bruta (PB), extrato etéreo (EE), fibra em detergente neutro (FDN), fibra em detergente ácido (FDA), proteína insolúvel em detergente neutro (PIDN), proteína insolúvel em detergente ácido (PIDA) e lignina $\left(\mathrm{H}_{2} \mathrm{SO}_{4} 72 \% \mathrm{p} / \mathrm{p}\right)$ obtidos seguindo os procedimentos descritos em Silva \& Queiroz (2002). O teor de fibra em detergente neutro corrigido para cinzas e proteína foi realizado segundo recomendações de Licitra et al. (1996) e Mertens (2002).

As estimativas dos teores de fibra em detergente neutro potencialmente digestível (FDNpD) e matéria seca potencialmente digestível (MSpD) dos alimentos foram obtidas de acordo com Paulino et al. (2006).

Os carboidratos totais (CT) foram estimados segundo Sniffen et al. (1992), como:

$\mathrm{CT}=100-(\% \mathrm{~PB}+\% \mathrm{EE}+\%$ cinzas $)$.

Os teores de carboidratos não-fibrosos corrigidos para cinzas e proteína (CNFcp) foram calculados como proposto por Hall (2003), sendo:

CNFcp $=(100-\% F D N c p-\% \mathrm{~PB}-\% \mathrm{EE}-\%$ cinzas $)$.

Os nutrientes digestíveis totais (NDT) foram calculados segundo Weiss (1999), mas utilizando a FDN e CNF corrigindo para cinza e proteína, pela seguinte equação: NDT $(\%)=$ PBD + FDNcpD + CNFcpD + 2,25EED . 
em que: $\mathrm{PBD}=\mathrm{PB}$ digestível; FDNcpD= FDNcp digestível; $\mathrm{CNF} c \mathrm{D}=\mathrm{CNF} c p$ digestíveis; e EED=EE digestível.

Os teores de nutrientes digestíveis totais estimados (NDTest) dos alimentos e dietas totais, foram calculados conforme equações descritas pelo NRC (2001).

Na estimação dos teores de MSi e FDNi das dietas, amostras dos alimentos fornecidos (cana e concentrado) foram incubadas por 240 horas (Casali et al., 2008) em duplicata (20 mg MS/ $/ \mathrm{cm}^{2}$ ) em sacos de tecido não-tecido (TNT - $100 \mathrm{~g} / \mathrm{m}^{2}$ ) no rúmen de dois novilhos mestiços recebendo dieta mista. Após este período, os sacos foram retirados, lavados em água corrente, e o material remanescente da incubação foi levado à estufa de ventilação forçada a $60{ }^{\circ} \mathrm{C}$ por 72 horas. Após esta etapa, foram retirados da estufa, acondicionados em dessecador e pesados, sendo o resíduo obtido considerado como MSi. Prosseguindo, os sacos foram, então, acondicionados em potes plásticos, adicionados $50 \mathrm{~mL}$ de detergente neutro por saco, e submetidos à fervura em detergente neutro por uma hora, sendo em seguida lavados com água quente e acetona, secos e pesados conforme o procedimento anterior, sendo o novo resíduo considerado como FDNi.

Nas análises estatísticas dos resultados, procedeu-se à decomposição da soma de quadrados relacionada às doses de óxido de cálcio na cana-de-açúcar, por meio de contrastes ortogonais (Tabela 3).

Ao primeiro contraste (A) atribuiu-se a comparação entre as médias do tratamento controle (cana in natura) e tratamentos envolvendo cana-de-açúcar com óxido de cálcio. Os contrastes representados pelas letras B e C permitiram a avaliação de efeitos de ordem linear e quadrática em função das doses de óxido de cálcio na cana-de-açúcar, respectivamente. Os procedimentos estatísticos foram realizados com o auxílio do programa SAS (1999), adotando-se 0,05 como nível crítico de probabilidade.

Tabela 3 - Distribuição dos coeficientes para os contrastes ortogonais empregados na decomposição da soma de quadrados para tratamentos

\begin{tabular}{ccccc}
\hline & \multicolumn{4}{c}{ Coeficiente } \\
\cline { 2 - 5 } Contraste & Cana in natura & 0,75 & 1,5 & 2,25 \\
\hline A & +3 & -1 & -1 & -1 \\
B & 0 & -1 & 0 & +1 \\
C & 0 & -1 & +2 & -1 \\
\hline
\end{tabular}

\section{Resultados e Discussão}

Em nenhum dos contrastes avaliados observou-se efeito $(\mathrm{P}>0,05)$ das doses de óxido de cálcio na cana-de-açúcar sobre o consumo de matéria seca, fibra em detergente neutro corrigida para cinza e proteína e variáveis comportamentais (Tabela 4).

Muitos são os fatores que podem afetar a ingestão de alimentos em ruminantes, provocando efeito direto no comportamento ingestivo, dentre eles o teor de FDN e a forma física da dieta, o que, segundo Van Soest (1994), pode afetar o tempo de ruminação. A ausência de efeito significativo nas atividades de ruminação, entretanto, pode ser explicada pela proximidade na composição das dietas (Tabela 2), uma vez que o volumoso e o concentrado foram os mesmos, diferenciando apenas pelas doses de óxido de cálcio utilizadas no tratamento químico da cana-de-açúcar.

O efeito da FDN sobre as atividades de alimentação, ruminação, mastigação e ócio foi observado por Carvalho et al. (2006a), os quais avaliaram diferentes níveis de FDN da forragem (20, 27, 34, 41 e 48\%) em dietas para caprinos e relataram elevação dos tempos despendidos em alimentação, ruminação e mastigação total, e diminuição do ócio. Os autores explicaram o ocorrido pela diminuição na densidade energética das dietas, ocasionada pela elevação do teor de FDN da forragem. No presente trabalho, não se observou efeito significativo $(\mathrm{P}>0,05)$ para os tempos de alimentação (Tabela 4), em função das doses de óxido de cálcio na cana-de-açúcar, sendo a média (264,9 min/dia) semelhante ao relatado por Carvalho et al. (2006a) em dietas com 27 e $34 \%$ de FDN da forragem, correspondendo a 36,6 e $43 \%$ na dieta total, valor de FDN próximos aos deste estudo.

Os valores médios obtidos para as atividades de ruminação, em min/dia, foram superiores aos valores relatados por Carvalho et al. (2006b) para diferentes níveis de FDN da forragem na dieta de caprinos, possivelmente pelo fato de ter usado feno de capim-tifton-85 como volumoso. A influência da qualidade do volumoso sobre a atividade de ruminação pode ser confirmada pelos teores de FDN na dieta total utilizada por Carvalho et al. (2006a), 49,4 e 55,9\%, respectivamente, nos níveis mais elevados de FDN da forragem (41 e 48\%), os quais foram superiores ao valor máximo de $41 \%$ de FDNcp, observado na dieta neste estudo, e, mesmo assim, os autores encontram menores tempos de ruminação.

Diante do exposto, fica claro que, além dos teores de FDN, a composição desta fibra também pode influenciar significativamente as atividades comportamentais, principalmente ruminação. Assim, dietas com teores de FDN similares, mas compostas por alimentos diferentes, podem predispor os animais a diferentes dispêndios nas atividades diárias. Van Soest (1994), no entanto, comentou que o tempo gasto em ruminação é proporcional ao teor de parede celular dos alimentos, ou seja, dietas com 
teores de FDN muito divergentes normalmente predispõem os animais a tempos de ruminação significativamente diferentes.

Os valores observados nas atividades de ruminação foram elevados e estão de acordo com as afirmações de Ribeiro (2003), o qual comentou que caprinos podem despender mais do que um terço do dia na atividade de ruminação. Além do teor de fibra, o comprimento da partícula da forragem, a quantidade de forragem consumida e o estresse térmico são alguns fatores que afetam o tempo de ruminação em caprinos (Ribeiro, 2003), os quais afetam secundariamente outros parâmetros do comportamento ingestivo como o tempo total em alimentação e ócio e as eficiências em alimentação e ruminação.

Em estudo com caprinos, conduzido por Carvalho et al. (2004), os autores avaliaram dietas contendo silagem de milho e concentrados com substituição parcial por farelo de cacau e torta de dendê e, do mesmo modo, não observaram diferença nos tempos de alimentação, ruminação e ócio. Devido às diferenças verificadas na ingestão de alimentos, os autores observaram alterações significativas na eficiência de ruminação, fato este não observado neste estudo (Tabela 5), sendo atribuído à ausência de efeito significativo $(\mathrm{P}>0,05)$ no consumo de MS.

Tabela 4 - Médias de quadrados mínimos, coeficiente de variação (CV, em \%) e indicativos de significância para os efeitos dos contrastes sobre o comportamento ingestivo em caprinos alimentados com dietas contendo cana-de-açúcar in natura ou tratada de óxido de cálcio $(\mathrm{CaO})$

\begin{tabular}{|c|c|c|c|c|c|c|c|c|}
\hline \multirow[t]{2}{*}{ Item } & \multicolumn{4}{|c|}{ Tratamento } & \multirow[b]{2}{*}{ CV (\%) } & \multicolumn{3}{|c|}{ Efeito $^{1}$} \\
\hline & Cana in natura & 0,75 & 1,5 & 2,25 & & Cana vs. $\mathrm{CaO}$ & Linear & Quadrático \\
\hline \multicolumn{9}{|c|}{ Consumo em 24 horas (kg) } \\
\hline CMS & 0,816 & 0,882 & 0,938 & 1,011 & 20,8 & ns & ns & ns \\
\hline CFDNcp & 0,294 & 0,330 & 0,330 & 0,325 & 23,7 & ns & ns & ns \\
\hline \multicolumn{9}{|c|}{ Alimentação } \\
\hline Min/dia & 267,5 & 251,3 & 276,9 & 263,8 & 21,2 & ns & ns & ns \\
\hline Min/kg MS & 345,8 & 295,1 & 304,1 & 265,5 & 22,6 & ns & ns & ns \\
\hline Min/kg FDNcp & 978,2 & 797,2 & 866,8 & 831,7 & 24,0 & ns & ns & ns \\
\hline \multicolumn{9}{|c|}{ Ruminação } \\
\hline Min/dia & 521,9 & 546,9 & 566,3 & 564,4 & 12,3 & ns & ns & ns \\
\hline Min/kg MS & 666,6 & 658,1 & 618,6 & 570,6 & 18,2 & ns & ns & ns \\
\hline Min/kg FDNcp & 1875,5 & 1778,1 & 1768,4 & 1789,5 & 19,6 & ns & ns & ns \\
\hline \multicolumn{9}{|c|}{ Mastigação } \\
\hline No/bolo & 113,8 & 115,9 & 114,8 & 118,4 & 14,1 & ns & ns & ns \\
\hline Seg/bolo & 62,1 & 67,7 & 66,7 & 68,1 & 14,9 & ns & ns & ns \\
\hline №/dia & 58030 & 56820 & 59205 & 58683 & 16,9 & ns & ns & ns \\
\hline Min/dia & 789,4 & 798,1 & 843,1 & 828,1 & 10,7 & ns & ns & ns \\
\hline Min/kg MS & 1012,4 & 953,2 & 922,7 & 836,1 & 15,8 & ns & ns & ns \\
\hline Min/kg FDNcp & 2853,7 & 2575,3 & 2635,3 & 2621,3 & 17,7 & ns & ns & ns \\
\hline \multicolumn{9}{|c|}{ Ócio } \\
\hline Min/dia & 650,6 & 641,9 & 596,9 & 611,9 & 13,9 & ns & ns & ns \\
\hline
\end{tabular}

1 ns: não-significativo ( $\mathrm{P}>0,05)$. Cana vs. $\mathrm{CaO}$ - controle (cana in natura) vs. cana com óxido de cálcio (CaO); L e Q - efeito linear e quadrático para as doses de óxido de cálcio na cana-de-açúcar.

Tabela 5 - Médias de quadrados mínimos, coeficiente de variação (CV, em \%) e indicativos de significância para os efeitos dos contrastes das eficiências de alimentação e ruminação em caprinos alimentados com dietas contendo cana-de-açúcar in natura ou tratada com óxido de cálcio $(\mathrm{CaO})$

\begin{tabular}{|c|c|c|c|c|c|c|c|c|}
\hline \multirow[t]{2}{*}{ Item } & \multicolumn{4}{|c|}{ Tratamento } & \multirow[b]{2}{*}{ CV (\%) } & \multicolumn{3}{|c|}{ Efeito $^{1}$} \\
\hline & Cana in natura & 0,75 & 1,5 & 2,25 & & Cana vs. $\mathrm{CaO}$ & Linear & Quadrático \\
\hline \multicolumn{9}{|c|}{ Eficiência de alimentação } \\
\hline g FDNcp/hora & 68,6 & 80,3 & 72,8 & 75,2 & 24,1 & ns & ns & ns \\
\hline \multicolumn{9}{|c|}{ Eficiência de ruminação } \\
\hline Bolos（nㅇdia) & 525,1 & 497,0 & 528,1 & 502,8 & 23,9 & ns & ns & ns \\
\hline g MS/hora & 95,4 & 97,8 & 99,4 & 108,7 & 21,0 & ns & ns & ns \\
\hline g FDNcp/hora & 34,2 & 36,4 & 34,9 & 35,0 & 22,1 & ns & ns & ns \\
\hline
\end{tabular}

1 ns: não-significativo ( $\mathrm{P}>0,05)$. Cana vs. $\mathrm{CaO}$ - controle (cana in natura) vs. cana com óxido de cálcio (CaO); L e Q - efeito linear e quadrático para as doses de óxido de cálcio na cana-de-açúcar. 
A ausência de efeito significativo $(\mathrm{P}>0,05)$ observada para as atividades de mastigação, em n\%/bolo, seg/bolo, $\mathrm{n} \%$ dia e min/dia, pode estar relacionada com a proximidade entre a composição química das dietas (Tabela 2), principalmente pela possível semelhança entre o tamanho de partículas dos alimentos, já que o processamento adotado foi o mesmo nas diferentes dietas experimentais. Essas pressuposições são suportadas pelos argumentos de Saenz (2005) de que o tamanho de partícula dos alimentos exerce grande efeito sobre as atividades de ruminação e mastigação. McLeod \& Minson (1988) comentaram, entretanto, que essas atividades de mastigação são mecanismos importantes no processo de redução do tamanho de partícula dos alimentos, respondendo por mais de $80 \%$ da quebra total de partículas.

A eficiência de alimentação não foi afetada significativamente $(\mathrm{P}>0,05)$ pelo uso do óxido de cálcio no tratamento químico da cana-de-açúcar (Tabela 5).

A eficiência de alimentação e ruminação apresenta relação direta com os níveis de ingestão de nutrientes dos animais. Assim, a ausência de efeito significativo para os consumos de MS e FDN pode ter contribuído para a obtenção da falta de relação observada nas eficiências de alimentação e ruminação sobre as doses de óxido de cálcio.

Neste estudo, os valores observados para os tempos de ruminação foram elevados e a eficiência de ruminação expressa em g de MS e FDNcp/hora não foram alteradas, podendo ser explicada pela ausência de efeito do óxido de cálcio sobre os tempos de alimentação e ruminação em 24 horas.

Os valores de eficiências de ruminação observados neste trabalho são inferiores aos valores relatados por Carvalho et al. (2004, 2006b) para caprinos. Atribuem-se as baixas eficiências de ruminação verificadas neste estudo ao teor de fibra da cana-de-açúcar, a qual normalmente é de lenta digestibilidade.

Não se observou efeito para o contraste cana in natura vs. cana com $\mathrm{CaO}$ sobre o número de períodos de alimentação, ruminação e ócio $(\mathrm{P}>0,05)$. Entretanto, recorrendo-se aos demais contrastes, observou-se efeito linear crescente e decrescente, respectivamente, para o número de períodos de alimentação e o tempo médio gasto por período. Isso aconteceu porque existe uma relação direta entre ambos, o aumento de um dessas variáveis implica na redução da outra (Tabela 6).

Os valores obtidos para o número de períodos de alimentação, ruminação e ócio observados neste trabalho estão de acordo com os relatados por Carvalho et al. (2004) para caprinos. Acredita-se que o valor nutritivo das dietas e a maior ou menor dificuldade dos caprinos em reduzir as partículas dos alimentos são os principais fatores a exercer efeito sobre o número de períodos de alimentação. Neste estudo, os animais apresentaram períodos de refeição similares, o que pode ser explicado pelo volumoso utilizado (cana-de-açúcar) ter sido o mesmo em todos os tratamentos. Vale ressaltar que a cana-de-açúcar foi tratada com óxido de cálcio e armazenada por 24 horas antes do oferecimento aos animais, porém, não houve efeito pronunciado sobre a composição das mesmas, o que proporcionou dietas com valores de composição química semelhantes.

O consumo médio de FDNcp por período de alimentação apresentou efeito linear positivo com a utilização das doses de óxido de cálcio na cana-de-açúcar (Tabela 6). Essa resposta ocorreu, provavelmente, em função dos valores observados para o tempo médio despendido por período de alimentação, a qual também foi afetada pelas doses de óxido de cálcio na cana-de-açúcar (Tabela 6).

Tabela 6 - Efeitos dos contrastes do número e tempo médio despendido por período nas atividades de alimentação, ruminação e ócio e consumo de MS e FDNcp por período de alimentação em caprinos alimentados com dietas contendo cana-de-açúcar in natura ou tratada com óxido de cálcio $(\mathrm{CaO})$

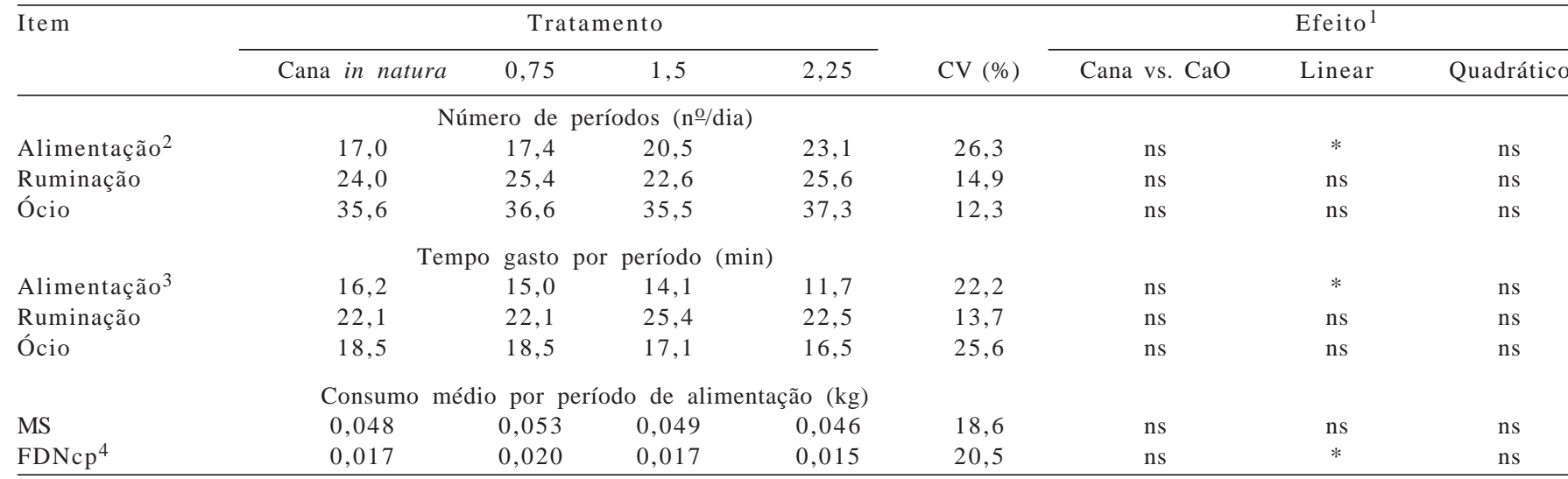

1 (ns) e (*): não-significativo (P>0,05) e significativo ao nível de 0,05 de probabilidade, respectivamente. C vs. CaO - controle (cana in natura) vs. cana com óxido de cálcio (CaO); L e Q - efeito linear e quadrático para as doses de $\mathrm{CaO}$ na cana-de-açúcar.

${ }^{2} \hat{Y}=14,5833+3,83333 X\left(r^{2}=0,9975\right) .{ }^{3} \hat{Y}=16,9778-2,19870 X\left(r^{2}=0,9339\right) ;{ }^{4} \hat{Y}=0,0219463-0,00324031 X\left(r^{2}=0,9999\right)$. 


\section{Conclusões}

As atividades diárias de alimentação, ruminação e ócio de caprinos em crescimento não são influenciadas pela utilização de dietas contendo cana-de-açúcar tratada com óxido de cálcio. O uso de óxido de cálcio no tratamento da cana-de-açúcar em doses de até 2,25\% não altera a eficiência de alimentação e ruminação em caprinos.

\section{Referências}

BALIEIRO NETO, G.; SIQUEIRA, G.R.; REIS, R.A. et al. Óxido de cálcio como aditivo na ensilagem de cana-de-açúcar. Revista Brasileira de Zootecnia, v.36, n.5, p.1231-1239, 2007.

CARVALHO, G.G.P.; PIRES, A.J.V.; SILVA, F.F. et al. Comportamento ingestivo de cabras leiteiras alimentadas com farelo de cacau ou torta de dendê. Pesquisa Agropecuária Brasileira, v.39, n.9, p.919-925, 2004.

CARVAlHO, G.G.P.; PIRES, A.J.V.; SILVA, R.R. et al. Comportamento ingestivo de ovinos Santa Inês alimentados com dietas contendo farelo de cacau. Revista Brasileira de Zootecnia, v.37, n.4, p.660-665, 2008.

CARVALHO, G.G.P.; PIRES, A.J.V.; SILVA, R.R. et al. Comportamento ingestivo de ovinos alimentados com dietas compostas de silagem de capim-elefante amonizada ou não e subprodutos agroindustriais. Revista Brasileira de Zootecnia, v.35, n.4, p.1805-1812, 2006 a.

CARVAlHO, S.; RODRIGUES, M.T.; BRANCO, R.H. et al. Comportamento ingestivo de cabras Alpinas em lactação alimentadas com dietas contendo diferentes níveis de fibra em detergente neutro proveniente da forragem. Revista Brasileira de Zootecnia, v.35, n.2, p.562-568, 2006b.

CASALI, A.O.; DETMANN, E.; VALADARES FILHO, S.C. et al. Influência do tempo de incubação e do tamanho de partículas sobre os teores de compostos indigestíveis em alimentos e fezes bovinas obtidos por procedimentos in situ. Revista Brasileira de Zootecnia, v.37, n.2, p.335-342, 2008.

EVANGELISTA, A.R.; PEREIRA, R.S.; ABREU, J.G. et al. Forragens para ovinos. In: VOLUMOSOS NA PRODUÇÃO DE RUMINANTES: VALOR ALIMENTÍCIO DE FORRAGENS, 1., 2003, Jaboticabal. Anais... Jaboticabal: Funep, 2003. p.193-239.
HALL, M.B. Challenges with non-fiber carbohydrate methods. Journal of Animal Science, v.81, n.12, p.3226-3232, 2003.

LICITRA, G.; HERNANDEZ, T.M.; VAN SOEST, P.J. Standardization of procedures for nitrogen fracionation of ruminant feed. Animal Feed Science Technological, v.57, n4, p.347-358, 1996.

McLEOD, M.N.; MINSON, D.J. Large particle breakdown by cattle eating ryegrass and alfalfa. Journal of Animal Science, v.66, n.4, p.992-999, 1988.

MERTENS, D.R. Gravimetric determination of amylase-treated neutral detergent fiber in feeds with refluxing in beakers or crucibles: collaborative study. Journal of AOAC International, v.85, n.6, p.1217-1240, 2002.

NATIONAL RESEARCH COUNCIL - NRC. Nutrient requirements of dairy cattle. 7.ed. Washington: National Academy Press, 2001. 450p.

NATIONAL RESEARCH COUNCIL - NRC. Nutrient requirements of small ruminants. Washington: National Academy Press, 2006. 362p.

PAULINO, M.F.; DETMANN, E.; VALADARES FILHO. S.C. Suplementação animal em pasto: energética ou proteica? In: SIMPÓSIO SOBRE MANEJO ESTRATÉGICO DA PASTAGEM, 3., 2006, Viçosa, MG. Anais... Viçosa, MG: SIMFOR, 2006. p.359-392.

RIBEIRO, S.D.A. Pastagens para caprinos. In: VOLUMOSOS NA PRODUÇÃO DE RUMINANTES: VALOR ALIMENTÍCIO DE FORRAGENS, 1., 2003, Jaboticabal. Anais... Jaboticabal: Funep, 2003. p.241-264.

RIBEIRO, L.S.O.; PIRES, A.J.V.; PINHO, B.D. et al. Valor nutritivo da cana-de-açúcar hidrolisada com hidróxido de sódio ou óxido de cálcio. Arquivo Brasileiro de Medicina Veterinária e Zootecnia, v.61, n.5, p.1156-1164, 2009.

SAENZ, E.A.C. Modelagem da redução do tamanho de partículas na alimentação de ruminantes. Ciência e Agrotecnologia, v.29, n.4, p.886-893, 2005.

SILVA, D.J.; QUEIROZ, A.C. Análise de alimentos: métodos químicos e biológicos. Viçosa, MG: UFV, 2002. 235p.

SNIFFEN, C.J.; O'CONNOR, D.J.; Van SOEST, P.J. et al. A net carbohydrate and protein system for evaluating cattle diets: carbohydrate and protein availability. Journal of Animal Science, v.70, n.12, p.3562-3577, 1992.

STATISTICAL ANALYSES SYSTEM - SAS. SAS user's guide. Cary: 1999. v.8, 295p.

VAN SOEST, P.J. Nutritional ecology of the ruminant. 2.ed. Ithaca: Cornell University Press, 1994. 476p.

WEISS, W.P. Energy prediction equations for ruminant feeds. In: CORNELL NUTRITION CONFERENCE FOR FEED MANUFACTURERS, 61., 1999, Ithaca. Proceedings... Ithaca: Cornell University, 1999. p.176-185. 